Events and situations of the past and the states associated with them are stored in memory and make up the content of the subjective experience. The experience of mental state allows a person to identify one's own states and the states of other people which contributes to personal and social interaction of children.

The experiences of children and adolescents with cerebral palsy are determined by their developmental disorders. The awareness of their disability determines a wide range of conditions: children may become disheartened and experience anxiety, fear, aggression, or timidity and shyness.

Children with severe speech disorders experience significant difficulties in differentiating and expressing personal emotions. They find it difficult to use mimic means for expressing basic emotions like surprise, fear, anger, joy, sadness. Children are not able to correctly express the emotional and semantic content of a statement.

The specificity of the subjective experience of mental states in children with developmental disorders has not been clearly studied; however, it is very significant in the process of adaptation and socialization of children

\section{Object characteristics.}

The experimental base for the study of the subjective experience consisted of children (10-12 individuals, 7-11 years old) and adolescents (10-13 individuals, 13-14 years old) with developmental disabilities (severe speech disorders, cerebral palsy) and intact intellect.

\section{Course of the study}

We studied the subjective experience of mental states of joy and anger, calm and indifference, fatigue and sadness. The subjects retrospectively and prospectively described their mental states in a free form Next, their answers were processed using the method of content analysis which helped to single out the semantic units.
The frequency of occurrence of substantial components of the subjective experience of mental states in children with cerebral pals

\begin{tabular}{|c|c|c|c|c|c|c|c|c|c|c|c|}
\hline & & & & Infantil & cere & tral pa & & & & & \\
\hline $7-10$ & years & ld $(\mathrm{m}$ & les) $(7 p$ & eople) & & & -10 yes & sold & femal & 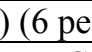 & \\
\hline \begin{tabular}{l}
\multicolumn{2}{c}{ Joy } \\
P
\end{tabular} & $\mathrm{P}^{\mathrm{Al}}$ & & $\frac{\mathrm{Ca}}{\mathrm{P}}$ & $\mathrm{lm}$ & № & & & & $\frac{1 \text { ger }}{\mathrm{F}}$ & $\frac{\mathrm{C}}{\mathrm{P}}$ & \\
\hline $\begin{array}{ll}4,4 & 2,1\end{array}$ & 2,4 & 1,6 & 1,9 & 1 & 1 & 0,8 & 1,7 & 1,5 & 0,8 & 0,5 & 1,2 \\
\hline $2,1 \quad 1,1$ & 1,6 & 0,7 & 1,1 & 0,7 & 2 & 1,2 & 1 & 0,3 & & 0,7 & 0,2 \\
\hline $\begin{array}{ll}0,6 & -- \\
21 & 04\end{array}$ & 0,1 & $\cdots$ & 0,3 & 0,1 & 3 & 0,3 & 0,2 & 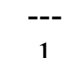 & 17 & 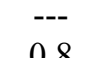 & 0,2 \\
\hline $\begin{array}{ll}2,1 & 0,4 \\
2 & 1,4\end{array}$ & $\begin{array}{c}2,1 \\
2\end{array}$ & $\begin{array}{l}1 \\
1,1\end{array}$ & $\begin{array}{l}2,6 \\
1,3\end{array}$ & $\begin{array}{l}0,8 \\
1\end{array}$ & $\begin{array}{l}4 \\
5\end{array}$ & $\begin{array}{l}1,8 \\
1,3\end{array}$ & $\begin{array}{c}1 \\
0,8\end{array}$ & $\begin{array}{l}1 \\
0,5\end{array}$ & $\begin{array}{l}1,7 \\
0,8\end{array}$ & $\begin{array}{l}0,8 \\
1,2\end{array}$ & $\begin{array}{l}1 \\
0,8\end{array}$ \\
\hline 3317 & 36 & 0,1 & $\begin{array}{l}0,7 \\
31\end{array}$ & $-3-$ & 6 & 12 & 13 & $-\cdots$ & 0,2 & 23 & 12 \\
\hline & , o & 0,1 & 0,1 & 0,6 & & 0,3 & & 0,2 & $\begin{array}{l}0,3 \\
0,3\end{array}$ & $2, J$ & 1,J \\
\hline 1 & 2,3 & 0,9 & 2 & 1,1 & & 0,2 & 0,8 & 0,3 & 0,2 & 0,2 & -- \\
\hline 0,3 & 0,1 & 0,4 & 0,3 & , & 10 & 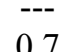 & 0,2 & $-\cdots$ & $-\cdots$ & 0,2 & $\cdots$ \\
\hline & 1,1 & 0,1 & 1,1 & 0,3 & 11 & 0,7 & 0.2 & 0,3 &,-3 & 0,3 & $\ldots$ \\
\hline $0,1 \quad--$ & $\begin{array}{l}0,4 \\
0,3\end{array}$ & $\ldots$ & $\begin{array}{l}0,3 \\
0,4\end{array}$ & -., & 13 & $\ldots$ & - & $\ldots$ & $\ldots$ & -- & 0,2 \\
\hline & & & & Infantil & $\frac{14}{\text { cere }}$ & $\begin{array}{l}0,2 \\
\text { tral pa }\end{array}$ & & & & & \\
\hline 13-14 & years & ld $(\mathrm{m}$ & les) (10 & & & & -14 ye & rs old & (fema & ) (3pe & \\
\hline$\frac{\text { Joy }}{\mathrm{D}}$ & $\mathrm{An}$ & & $\frac{\mathrm{Cal}}{\mathrm{p} \text { pal }}$ & $\mathrm{m}$ & № & $\mathrm{J}$ & oy & & ger & & $m$ \\
\hline & 2.4 & 1.2 & 1.3 & 1.6 & & 1 & & 1.7 & 0.3 & 1.7 & \\
\hline & & 0,1 & 0,3 & 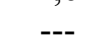 & 2 & $\ldots$ & 0,7 & 0,7 & 0,3 & 0,7 & 0,7 \\
\hline $0,6 \quad 0,2$ & 0,1 & & & -- & 3 & 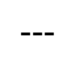 & & 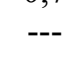 & & 0,3 & \\
\hline & 1,4 & 0,7 & 0,8 & 0,3 & & 2,3 & 0,3 & 2 & 0,3 & 2,3 & 0,3 \\
\hline & 0.9 & 1,4 & , & 0.8 & 5 & 0,7 & 1 & 0,3 & 0,1 & 1 & 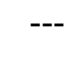 \\
\hline $\begin{array}{ll}---1.8 \\
\end{array}$ & 0,6 & 1.3 & 0, & $\begin{array}{l}0,1 \\
1.7\end{array}$ & $\begin{array}{l}6 \\
7\end{array}$ & 1 & 0.7 & 0,7 & $\begin{array}{l}0,7 \\
1.7\end{array}$ & 1 & --- \\
\hline 0,2 & 0,2 & 0,1 & 1,1 & 0,1 & 8 & 0,3 & & 0,3 & 0,3 & 0,7 & \\
\hline & 0,5 & 0,7 & 0,8 & 1,2 & 9 & 0,7 & --- & 1,3 & 0,7 & 0,7 & 0,7 \\
\hline & 0,6 & 0,2 & 0,2 & 0,3 & 10 & & 1 & 1 & 0,3 & 0,3 & 0,3 \\
\hline 0,4 & 1 & 0,5 & 0,7 & 0,3 & 11 & 1,3 & $\cdots$ & 1 & 0,3 & $\cdots$ & $\cdots$ \\
\hline $0,2 \quad 0,2$ & 0,3 & o, 0,3 & 0,3 & $\ldots$ & 13 & $\cdots$ & --- & 0,3 & $\ldots$ & --- & 0,3 \\
\hline & & & & & & & & & & & \\
\hline
\end{tabular}

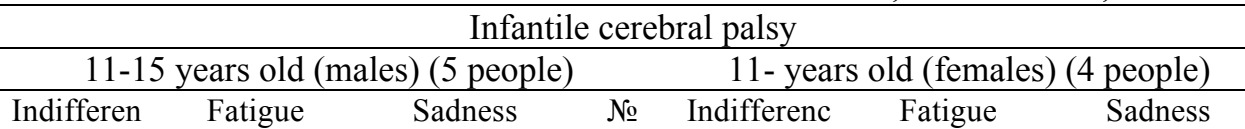

\begin{tabular}{|c|c|c|c|c|c|c|c|c|c|c|c|}
\hline e & & & & & & & - & & & & \\
\hline & $\mathrm{P}$ & $\mathrm{F}$ & $P$ & F & & $\mathrm{P}$ & & $\mathrm{P}$ & $\mathrm{F}$ & & \\
\hline 0.8 & 0,8 & -- & 0,4 & 0,4 & 1 & $\begin{array}{c}1 \\
0.3\end{array}$ & $\begin{array}{l}0,5 \\
0,\end{array}$ & & & & \\
\hline & & & & & & & & --. & & & \\
\hline & 0,2 & - & & & & & & & & & \\
\hline & & & & & 3 & $\begin{array}{l}0,5 \\
--.5\end{array}$ & 0,3 & & & & \\
\hline & $\begin{array}{l}0, \\
0,\end{array}$ & $\begin{array}{l}0 \\
0 \\
0\end{array}$ & & & & & 0,3 & 2,5 & & & \\
\hline & 1 & 0,6 & 0,2 & 0,2 & & & & 0.3 & & 0,5 & \\
\hline
\end{tabular}

Legend: $\mathrm{P}$ - past time; $\mathrm{F}$ - future time

semantic units of texts describing mental states: 1 . assessment / quantity / comparison; 2. relatives / close relationships; 3 . unity / acceptance; 4 . feelings / emotions / experiences; 5. causes / situations; 6 . regulation; 7. actions / activities; 8 . mental, mnemic and reflexive processes; 9 . conditions / location of events: 10. wishes / dreams / expectations; 11. reactions behavior; 12. physiological processes; 13. communication; 14. abstraction
The frequency of occurrence of substantial components of the subjective experience of mental states in children with severe speech disorders

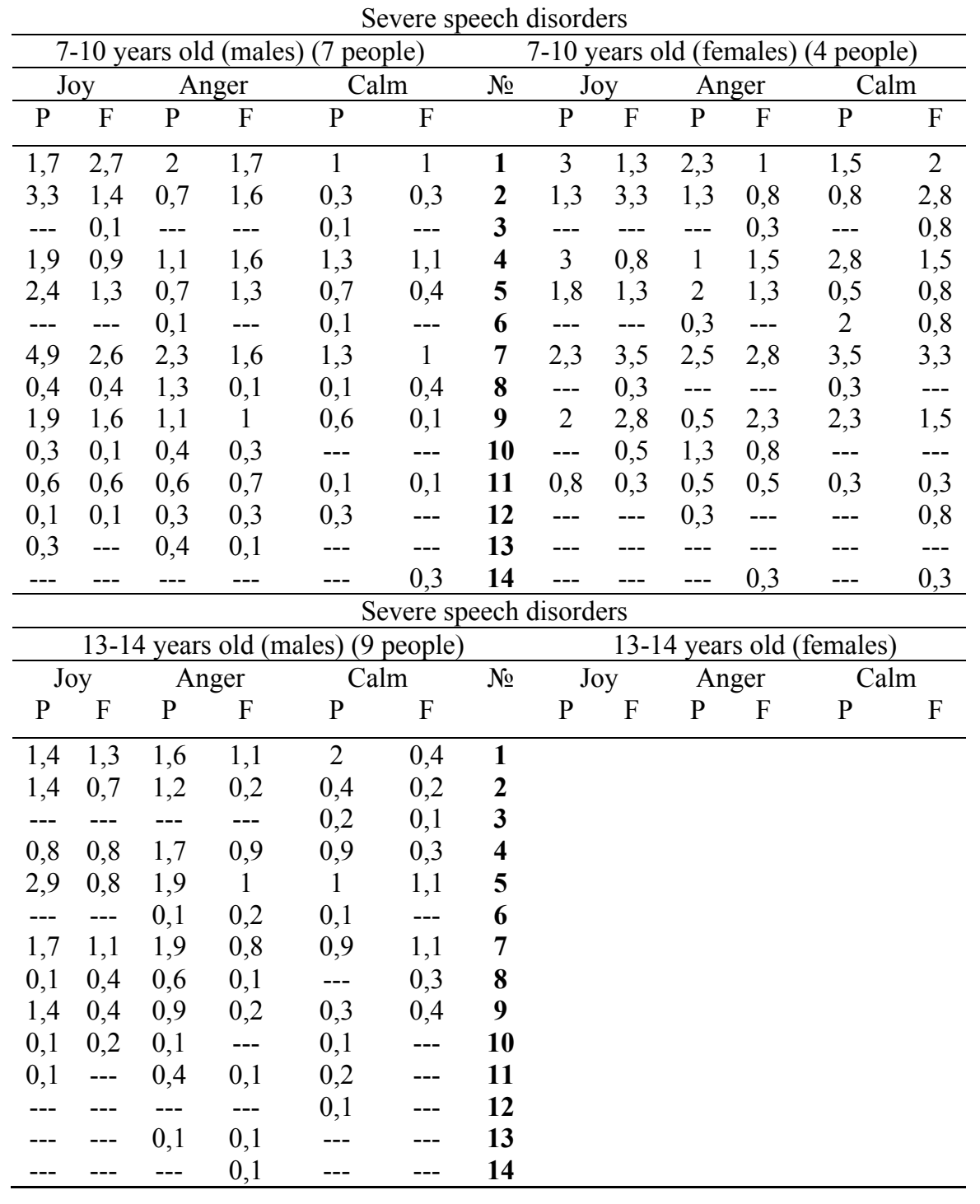

The subjective experience of the studied mental states has substantial specificity which depends on gender and age. Separating the core and peripheral layers of the structure of experience will make it possible to make forecasts and ways of regulating states in the future.Core formations (if they are similar in the studied groups) help to identify and differentiate one's own mental states and states of other people. Peripheral layers bring diversity to the subjective experience and determine its specificity for each state.

Funding: The research was financially supported by the grant of the Russian Foundation for Basic Research, project No. 18-013-01012 "Subjective experience of mental states in a life prediction situation"
Conclusion

1.The subjective experience of the states of joy, anger and calm in child and adolescent boys is represented by the same characteristics. The experience of girls is substantially more diverse. The experience of the states of joy, anger, and calm in the future is represented by similar descriptions in boys and girls.

2.The subjective experience of the states of indifference and sadness has a similar content in boys and adolescent girls. The experience of fatigue differs in terms of content, and adolescent girls describe this condition very shortly.

3.The subjective experience of the states of boys with SSD in the past is represented by a smaller number of operands, while girls describe the state of joy and calm in the future in a more comprehensive and meaningful manner.

4.Boys and girls reveal the content of the past experience of the state of anger using common operands. In other words, the experience has a similar content.

References:

1.Izotova, E.K.; Nikiforova, E.V. Emotional sphere of the child: theory and practice; Publisher: Akademiya, Russia, 2004; $\mathrm{p}$.
280 2.lzard, K.E. Psychology of emotions; Publisher: Piter, Russia, 2010; p. 464

tishcheva, L.V. The Experience Of Mental States Of Adolescents Orphans. European Proceedings of Social and
Behavioural Sciences EpSBS, 2018, Volume XLV (45), pp. $317-325$

4.Kuznetsova, L.V.; Peresleni, L.I. Basics of Special Psychology: Study Guide; Akademiya, Russia, 2002; p.480

amorokova, L.A. Peculiarities of the emotional sphere in age. International Student Science Journa 2015, 6, URL: http://www.eduherald.ru/ru/larticle/view?id=13557

6.Kondratenko, I.Yu. Features of mastering the emotional vocabulary of older preschool children with a general $51-59$

7.Shipitsina, L.M.; Volkova, L.S. Some features of emotional and personal qualities in younger schoolchildren with general speech underdevelopment. Defectology, 1993, 4, pp. 43-48. Dubrynina, T. Ye. Features of the emotional-volitional sphere in preschool age. Scientific community of students of the $X X \mid$ century. Humanitarian sciences, 2017, 1, pp. 24-29

9.Yurchuk, E.N. Emotional development of preschool children Guidelines; Publisher: Sfera, Russia, 2008; p. 128

peral preschool children with a general underde.
speech. Young Scientist, 2018, 27, pp. 146-148. 